\title{
Corridor consultations and the medical microbiological record: is patient safety at risk?
}

\section{S R Heard, C Roberts, S J Furrows, M Kelsey, L Southgate, on behalf of the Specialty Assessment Working Group for Medical Microbiology of the GMC}

See end of article for authors' affiliations

.....................

Correspondence to: Dr S Heard, London Deanery, 20 Guilford

Street, London,

WCIN IDZ, UK

sheard@londondeanery.ac.uk

Accepted for publication

17 September 2002
The performance procedures of the General Medical Council are aimed at identifying seriously deficient performance in a doctor. The performance procedures require the medical record to be of a standard that enables the next doctor seeing the patient to give adequate care based on the available information. Setting standards for microbiological record keeping has proved difficult. Over one fifth of practising medical microbiologists (including virologists) in the UK (139 of 676) responded to a survey undertaken by the working group developing the performance procedures for microbiology, to identify current practice and to develop recommendations for agreement within the profession about the standards of the microbiological record. The cumulative frequency for the surveyed recording methods used indicated that at various times $65 \%$ (90 of 139) of respondents used a daybook, $62 \%$ (86 of 139) used the back of the clinical request card, $57 \%$ (79 of 139) used a computer record, and $22 \%$ (30 of 139) used an index card system to record microbiological advice, suggesting wide variability in relation to how medical microbiologists maintain clinical records.
$\mathrm{T}$ he performance procedures of the General Medical Council (GMC) are aimed at identifying seriously deficient performance in a doctor. Serious deficient performance is defined by the GMC as "departure from good professional practice sufficiently serious to call into question the doctor's registration". ${ }^{1}$ The performance procedures have been developed for each specialty by small working parties known as "specialty assessment working groups" (SAWGs). These were established by the GMC for each medical discipline to develop and test a series of assessment instruments according to a standardised protocol that is adapted for the specialty. The groups are chaired by a senior clinician and include active lay participation at every step of development. ${ }^{2}$

"Well kept medical records are an important component of good risk management and clinical governance"

The procedures recognise that record keeping is a fundamental component of medical practice. It is required to document what has taken place between a medical practitioner and the patient. It serves as a permanent and ongoing statement about the patient's condition, assessment, and management. The medical record also has an important medicolegal status when questions about the management and delivery of patient care are raised. ${ }^{3}$ Finally, well kept medical records are an important component of good risk management ${ }^{4}$ and clinical governance.

The performance procedures require the medical record to be assessed to answer the basic question: "If I were the next doctor to see this patient, would this record enable me to give adequate care by giving me systematic and ready access to all the information I require?" ${ }^{5}$ This question was developed first and particularly in the context of general practice but has been extended as a fundamental component of the procedures for all specialties. The review of the medical record provides the basis of selection of the cases upon which the doctor is subsequently peer assessed for his/her medical management of patients (case based orals).

To date, the view taken by the GMC is that this practice is transferable among the specialties. However, in developing the performance procedures for medical microbiology the SAWG for medical microbiology has identified problems within the specialty around the medical microbiology record. Because medical microbiology is fundamentally a referral and consultative service, the patient record is not the responsibility of the medical microbiologist, but of the primary clinician. Nonetheless, the medical microbiologist is responsible for interpreting laboratory data and for making recommendations about patient management that is usually taken up by the clinician responsible for the care of the patient. This is most commonly with regard to treatment for a diagnosed or possible infection (for example, antibiotic recommendations), but may also involve infection control management and investigative advice.

It is also necessary to consider the environment in which advice is offered and the recipient of such advice. Clinical "corridor or car park consultations" culminating in clinical advice are common. This is relevant not only in microbiological practice, but is part of the daily discourse of hospital medicine. Should all such conversations be followed by a bedside visit and a note in the patients' record? And are telephone consultations in which clinical advice is given similarly to be regularly recorded? Given that clinical practitioners who are not medically qualified often request such advice, is it appropriate to assume in every instance that the recipient has the vocabulary and heuristic knowledge to place microbiological advice in its appropriate context?

When the SAWG came to look at the microbiological record within the context of the medical microbiology performance procedures a problem immediately became apparent-just what is the microbiological record? Whereas other specialties have been able to identify standards for the clinical record relevant to the specialty, ${ }^{5}$ there is less information available on how pathologists record their advice/actions at the clinical-

Abbreviations: GMC, General Medical Council; SAWG, Specialty Assessment Working Group 
1. Name (optional) Grade Gender $\quad M / F$

2. Main sphere of clinical practice: Microbiology $\square$ Virology $\square$ Infection control $\square$ Other $\square$

3. Name of hospital

4. Do you believe that you regularly keep a contemporaneous record of clinical advice/recommendations/interventions? Yes No

5. Do you use one method to record clinical advice or a number of different methods? One method $\square \quad$ Different methods

6. Please identify the approach that you use to record the clinical microbiology/virology record.

a) Day book to record clinical advice

b) Back of clinical request card

d) Index card system

e) Patients' notes:

c) Computer record

Yes

No

If yes, please indicate on the scale below the percentage of all clinical advice given that you believe you record in this way.

\begin{tabular}{ccccc} 
& & & $\mid$ & \\
\hline & $25 \%$ & $50 \%$ & $75 \%$ & $100 \%$
\end{tabular}

Yes $\square$ No $\square$

If yes, please indicate on the scale below the percentage of all clinical advice given that you believe you record in this way.

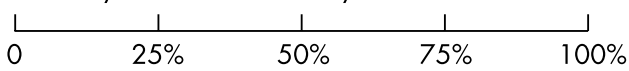

Yes

No $\square$

If yes, please indicate on the scale below the percentage of all clinical advice given that you believe you record in this way.

\begin{tabular}{ccccc} 
& & & & \\
\hline & $25 \%$ & $50 \%$ & $75 \%$ & $100 \%$
\end{tabular}

Yes $\square$ No $\square$ If yes, please indicate on the scale below the percentage of all clinical advice given that you believe you record in this way.

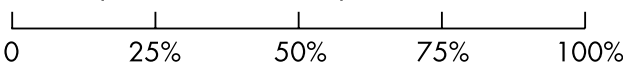

i. Do you regularly record clinical advice in patients' notes?

Yes No $\square$

ii. If yes, is this for all patients for whom you give clinical advice or only for selected patients?

\section{All} Selected

iii. If you write in the clinical notes for selected patients, are these patients with:

i. A positive microbiology/virology laboratory result.
All $\square$
None
Some

ii. Patients about whom clinical advice is specifically requested.

All $\square \quad$ None $\square$ Some

f) Do you use other ways to record clinical advice:

Yes

No

Please describe:

g) If you give advice on more than one hospital site, how do you record this?

7. Do you think your approach to keeping microbiology/virology clinical records meets the standard set by the GMC, i.e. that another microbiologist/virologist can use the record you have left to benefit the patient with respect to microbiology/virology clinical advice/care?

$$
\text { Yes } \square \text { No }
$$

8. Do you think that guidelines should be developed to help microbiologists adopt a clearer and more accountable approach to the microbiology clinical record?

$$
\text { Yes } \square \text { No }
$$

9. Please indicate your ideas as to how this might be achieved and what you think they should include.

Figure 1 Questionnaire on the clinical microbiology/virology record.

pathological interface. Histopathologists and cytologists provide a clear example of how their reports and advice are presented and retained. Haematologists, with dual clinical and laboratory responsibilities, successfully manage to channel laboratory advice, which may be additional to the laboratory report, into the overall patient record. The medical microbiol- ogist is also responsible for issuing laboratory reports, but in addition to interpreting and advising on the report may be asked by a variety of clinicians, in a variety of circumstances, for clinical advice on patient care. However, this advice is recorded in a variety of ways, with medical microbiologists using a combination of daybooks, laboratory cards, index card 


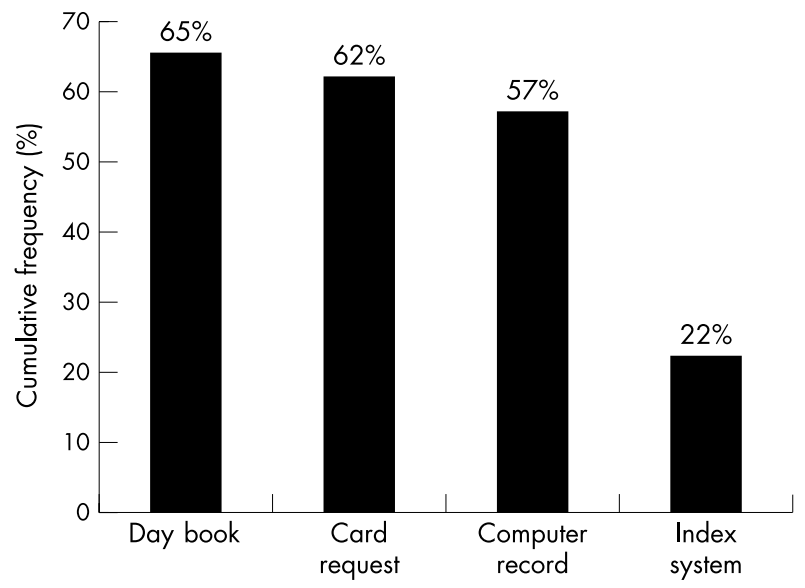

Figure 2 Cumulative responses to recording methodology used.

systems, personal diaries, computer records, and patients' note in some circumstances.

\begin{abstract}
"The specialty assessment working group for medical microbiology has identified problems within the specialty around the medical microbiology record"
\end{abstract}

Against this background, setting standards for microbiological record keeping has proved to be difficult. If the assumption is that microbiological clinical advice should be consistently and robustly recorded, especially against the minimum criteria set by the GMC, then the specialty needs to consider the way in which this can be achieved. A survey of practising medical microbiologists (including virologists) was undertaken by the members of the SAWG to identify current practice and develop recommendations for agreement within the profession about the standards of the microbiological record.

\section{METHODOLOGY}

A questionnaire developed by the microbiology SAWG of the GMC was sent to 178 medical microbiologists practising in the UK (fig 1). Choosing every fifth name in the Royal College of Pathologists' Handbook initially identified a representative sample of practising medical microbiologists. Subsequently, individuals who were not medically trained or were not currently in microbiology clinical practice, did not have a UK address, or did not offer an e-mail address were excluded from receiving the survey. Although doctors who were based at the Public Health Laboratory Service (Colindale, UK) were not included, doctors at other public health laboratories providing day to day clinical liaison were invited to complete the survey.

The initial trawl through the handbook, taking every fifth eligible name, generated 152 names. To increase the sample size, a further 26 names were selected from the same eligible group. These names were spread evenly through the alphabet and the individuals concerned were based at hospitals that had not already been included in the sample. This increased the representation in the survey of district general hospitals and helped to prevent a bias towards teaching hospital practice. The GMC sent the survey to practitioners and GMC headed paper was used to make the request for return of the survey. Respondents were not required to give either their name or identify their hospital and hence follow up of non-responders was not possible.

The survey asked respondents to indicate the methods used to record microbiological advice and the frequency with which advice was recorded in this way. The categories of record methodology were not mutually exclusive and more than one method could be indicated.

Responses on returned surveys were coded, entered on to a database, and subsequently analysed by SPSS (version 11 ), a comprehensive database and statistical package.

\section{RESULTS}

Of the 178 survey requests sent out, five were returned by the post office and four were returned by doctors not practising microbiology. One hundred and thirty nine completed surveys were received, a response rate of $82 \%$ (139 of 169). The Royal College of Pathologists has identified that there are 676 practising microbiologists on its database, so that the survey responses received represent over one fifth $(21 \%)$ of practising microbiologists in the UK.

Table 1 shows the frequency with which respondents used one approach or another in recording advice. The cumulative frequencies for each approach indicated that 65\% (90 of 139) of respondents used a daybook, $62 \%$ (86 of 139) used the back of the clinical request card, 57\% (79 of 139) used a computer record, and 22\% (30 of 139) used an index card system to record microbiological advice ( fig 2 ).

Seventy two percent of respondents (100 of 139) regularly recorded advice in patients' notes (table 2 ). Five respondents $(3.6 \%)$ did this for all patients for whom clinical advice was given and $71 \%$ of respondents (99 of 139) recorded advice on selected patients. Approximately $25 \%$ of those surveyed did not respond to the question. Of those writing in patients' notes, 14 did so for all patients with a positive microbiology result, four respondents never did so, and 96 did so for some patients with positive results. Thirty percent of respondents (42 of 139) always wrote in the notes of patients about whom clinical advice had been specifically requested and 55\% (76 of 139) wrote in some patients' notes when clinical advice was requested. Twenty one (15\%) of those surveyed did not respond to this question.

Respondents cited several other methods of recording microbiological information. These included paper sheets, books (for example on call/ITU book, etc), letters, comments added to reports, palmtop computers, and tape recordings. Eighty two per cent of questionnaire respondents ( 114 of 139) believed that guidelines should be developed to help microbiologists adopt a clearer and more accountable approach to the microbiology clinical record.

\section{DISCUSSION AND RECOMMENDATIONS}

Our survey of medical microbiologists was undertaken to explore clinical practice with respect to record keeping. There

Table 1 Percentage of occasions when method was used to record microbiological advice

\begin{tabular}{lllcl}
\hline Methodology & $1-25 \%$ & $26-50 \%$ & $51-75 \%$ & $76-100 \%$ \\
\hline Daybook & $21.6(30 / 139)$ & $17.3(24 / 139)$ & $16.5(23 / 139)$ & $9.4(13 / 139)$ \\
Request form & $38.8(54 / 139)$ & $11.5(16 / 139)$ & $5.0(7 / 139)$ & $0.7(1 / 139)$ \\
Computer & $34.5(48 / 139)$ & $12.2(17 / 139)$ & $4.3(6 / 139)$ & $5.8(8 / 139)$ \\
Index cards & $8.6(12 / 139)$ & $2.2(3 / 139)$ & $5.0(7 / 139)$ & $5.0(7 / 139)$ \\
\hline
\end{tabular}




\begin{tabular}{lc} 
Table 2 Recording in patients' notes & \\
\hline Question & \multicolumn{1}{c}{ Frequency (\%) } \\
\hline Do you regularly record clinical advice in patients' notes? & $100 / 139(72)$ \\
Yes & $39 / 139(28)$ \\
No & \\
If yes, is this for all patients for whom you give clinical advice or only \\
for selected patients? & $5 / 139(3.6)$ \\
All & $99 / 139(71)$ \\
Selected & $35 / 139(25)$ \\
No response & \\
If you write in the clinical notes for selected patient, are these patients \\
with: & $14 / 139(10)$ \\
A positive microbiological/virology laboratory result? \\
All & $4 / 139(3)$ \\
None & $96 / 139(29)$ \\
Some & $35 / 139(18)$ \\
No response & $42 / 139(30)$ \\
Patients about whom clinical advice is requested? & \\
All & $76 / 139(55)$ \\
Some & $21 / 139(15)$ \\
No response &
\end{tabular}

was an impressively high response rate, perhaps because of the involvement of the GMC. A legitimate question, which was asked by several of those responding, was whether record keeping for clinical advice mattered in the context of microbiological advice. After all, the laboratory record of results stands as the outcome of the investigations of the patient. What further, one might ask, is required, given that the clinician with responsibility for the patient takes the clinical decision around further investigation, prescribing, and treatment? This cuts to the heart of the clinical role of the medical microbiologist. If the medical microbiologist is genuinely part of the clinical team contributing to the effectiveness of clinical care, then he/she must take on that responsibility fully. If the clinical advice given by the microbiologist is going to make a difference to the care a patient receives and if that advice is acted upon (or not, as the case may be), then it should become part of the record of that patient's care. Standard 4 of the Clinical Negligence Scheme for Trusts indicates that: "A patient's health record should inform any clinician who has a responsibility for the patient of all the key features which might influence the treatment proposed."

\section{"Most medical microbiologists use several approaches to record clinical advice but there are no clear standards against which the documentation of this advice can be assessed"}

The issue then becomes one of logistics rather than accountability-because it is difficult to do this, the importance of finding an appropriate methodology and setting standards for it should not be discounted.

Our survey demonstrates that microbiologists across the UK record clinical advice in a variety of ways. Most medical microbiologists use several approaches to record clinical advice but there are no clear standards against which the documentation of this advice can be assessed. This may become increasingly relevant in the context of multiprofessional ward rounds where advice may be given/heard not only by medical staff but also by other healthcare professionals. It can have important potential implications for risk management and for clinical governance, especially at a time when hospital cross infection and its consequences have a high political and patient interest profile. ${ }^{7}$ For example, giving verbal advice to doctors in training or to nurse prescribers, which is not written down and may therefore be misunderstood/ misinterpreted is a potential concern. Is the patient (and perhaps the medical microbiologist) at risk from verbal or

\section{Take home messages}

- The results of our survey are representative of over one fifth of practising medical microbiologists (including virologists) in the UK identify current practice

- The cumulative frequency for the surveyed recording methods used indicated that at various times $65 \%$ of respondents used a daybook, $62 \%$ used the back of the clinical request card, $57 \%$ used a computer record, and $22 \%$ used an index card system to record microbiological advice

- Thus, microbiologists across the UK record clinical advice in a variety of ways

- Most medical microbiologists use several approaches to record clinical advice but there are no clear standards against which the documentation of this advice can be assessed and this may become increasingly relevant in the context of multiprofessional ward rounds where advice may be given/heard not only by medical staff but also by other healthcare professionals

- It may also have important potential implications for risk management and for clinical governance

- Recommendations should be developed within the profession about the standards of the microbiological record

telephoned advice being incorrectly understood and recorded in the clinical record? Should the entry into the patient record perhaps be checked subsequently by the medical microbiologist or at least a record of the advice given be recorded elsewhere by the medical microbiologist? We have attempted to consider several of these issues both pragmatically and from the viewpoint of clinical risk and would recommend the following:

(1) Microbiologists should recognise and accept the need for adequate and accessible clinical records.

(2) Microbiologists should decide on the type, quantity, and quality of information that is required to reflect a clinical consultation.

(3) Microbiologists should make relevant notes in patients' records, especially in clinical situations such as endocarditis, meningitis, significant bacteraemias, intensive care infections, and nosocomial infections prolonging hospital stay.

(4) Microbiologists should recognise the diverse means of recording information.

(5) Microbiologists should keep a suitable laboratory record for continuity of care by fellow microbiologists that is standardised and recorded without jargon, obscure abbreviations, or acronyms. This can be in a laboratory book, using a card system, or in an electronic format.

(6) Clinical advice given over the telephone or "in the corridor" should be regularly recorded. This can be in a laboratory book, using a card system, or in an electronic format.

(7) Every entry should include: date/time, patient details, recipient of information, advice given, clearly printed name of microbiologist.

(8) Microbiologists should develop a "sixth sense" about those patients or incidents when exceptional records will be invaluable.

(9) Records of outbreaks should be kept carefully with all incidents fully documented.

The issues raised by this survey are of particular relevance to microbiologists, but also raise wider concerns for the medical profession. Clinical discussion and exchanges are part of the bread and butter of clinical life; advice about patients given in such circumstances may be taken, may be misinterpreted, or may be misunderstood. Patients may or may not benefit and often the advice may not be recorded. What are the risks of such clinical behaviours? Do patients benefit from the wider and greater breadth that such advice may afford? Should clinicians refuse to discuss patients outside the formal setting of 
a referral? The loss to patient care and to clinical practice could potentially be enormous. Perhaps it is necessary for the profession to consider the overall risk and loss to patient care were such exchanges lost, but at the same time, to assess the consequence of such exchanges taking place informally and as undocumented episodes of clinical care.

\section{Authors' affiliations}

S R Heard, S J Furrows, London Deanery, 20 Guilford Street, London, WCIN IDZ, UK

C Roberts, Level 6, Medical Microbiology, John Radcliffe Hospital,

Headington, Oxford OX3 9DU, UK

M Kelsey, Department of Microbiology, Whittington Hospital, Highgate, London N19 5NF, UK

L Southgate, Performance Assessment Implementation Group, General Medical Council, Great Portland St, London WIN 6JE, UK

\section{REFERENCES}

1 General Medical Council. Performance procedures-a guide to the arrangements. London: General Medical Council, 1999.

2 Southgate L, Cox J, David T, et al. The assessment of poorly performing doctors: the development of the assessment programmes for the $\mathrm{GMC}^{\prime} \mathrm{s}$ performance procedures. Med Educ 2001;35(suppl 1):2-8

3 The National Health Service Litigation Authority. Clinical Negligence Scheme for Trusts. Clinical risk management standards. June 2002. London: NHSLA.

4 Department of Health. HSC 1999/065. Clinical governance for the new NHS. London: Department of Health, 1999.

5 Southgate L, Cox J, David T, et al. The General Medical Council's performance procedures: peer review of performance in the workplace. Med Educ 2001;35(suppl.1):9-19.

6 The National Health Service Litigation Authority. Clinical negligence scheme for trusts. Clinical risk management standards (standard 4). June 2000. London: NHSLA.

7 Department of Health. Getting ahead of the curve-a strategy for infectious diseases (including other aspects of health protection). London: Department of Health, April 2001.

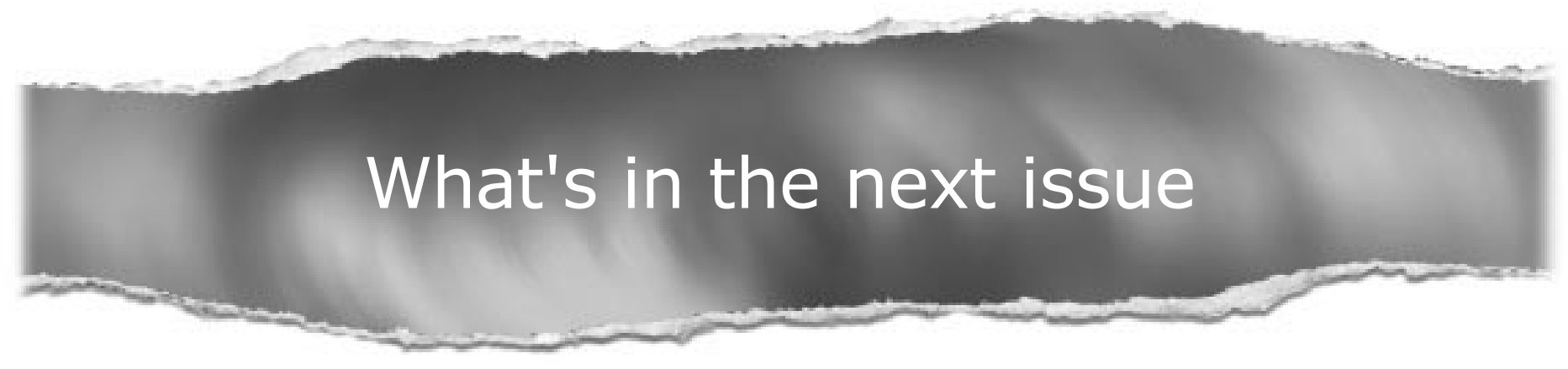

\section{Future content}

See which articles have just been accepted for publication and preview the table of contents for the next issue a month before it is published

\section{www.jclinpath.com}

